UMR

PATENT POOLS AND THE DYNAMiC INCENTIVES TO R\&D

Vianney DEQUIEDT ; Bruno VERSAEVEL

Working Paper GAEL ; 2004-12

- September 2004 -

Institut National de la Recherche Agronomique - Université Pierre Mendès France Unité Mixte de Recherche 1215

Domaine Universitaire - BP 47 - 38040 GRENOBLE Cedex 9

Tél. : 33 (0) 476825439 - Fax : 33 (0) 476825455

E-mail : vertier@grenoble.inra.fr - http://www.grenoble.inra.fr

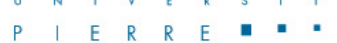

$M$ E N D

f R A N C E " -

Grenoble 2 Sciences Sociales 


\title{
Patent Pools and the Dynamic Incentives to R\&D
}

\author{
by
}

Vianney Dequiedt ${ }^{1}$ and Bruno Versaevel $^{2}$

Preliminary version: September 2004

\begin{abstract}
Patent pools are cooperative agreements between several patent owners to bundle the sale of their respective licenses. In this paper we analyze their consequences on the speed of the innovation process. We adopt an ex ante perspective and study the impact of possible pool formation on the incentives to innovate. Because participation in the creation of a pool acts as a bonus reward on R\&D activity, we show that a firm's investment pattern is upward sloping over time before pool formation, and decreases afterwards. The smaller the set of initial contributors, the higher this effect. A pool formation mechanism based on a proposal by the industry and acceptance/refusal by the competition authority may induce overinvestment in early innovations and lead to a delayed clearance date, that is suboptimal from an ex ante viewpoint.
\end{abstract}

Keywords: Licensing, R\&D races, Innovation, Competition policy.

JEL: L51, O32.

\footnotetext{
${ }^{1}$ INRA GAEL, email: dequiedt@grenoble.inra.fr

${ }^{2}$ EM Lyon and GATE, email: versaevel@em-lyon.com
} 


\section{Introduction}

Patent pools are cooperative agreements among several patent owners to license in a package a group of their respective patents to third parties. ${ }^{1}$ Although patent pools have long been suspected of facilitating the implementation of anti-competitive behavior, recent communications by competition authorities recognize the potential virtues of patent pools as a means of improving social welfare. ${ }^{2}$ In the Antitrust Guidelines for the Licensing of Intellectual Property (1995), patent pools are declared to "provide procompetitive benefits by integrating complementary technologies, reducing transaction costs, clearing blocking positions, and avoiding costly infringement litigation" (p. 28). ${ }^{3}$ In substance, by allowing one-stop shopping, the pool gives access to more efficient licensing. It can thus increase the private value of the constitutive patents, and also increase social welfare by facilitating the diffusion of cost-reducing or demandenhancing technology. As a consequence of this more favorable position, patent pools re-emerged in the recent years, mainly in high-technology sectors. Examples include MPEG-2 Digital Video (1997), DVD-ROM and DVD-Video (1998, 1999), and 3G-Mobile Communications (2001).

\footnotetext{
${ }^{1}$ The U.S. Antitrust Guidelines for the Licensing of Intellectual Property (1995), issued jointly by the Department of Justice (DoJ) and the Federal Trade Commission (FTC), evoke cross-licensing and pooling arrangements, indistinguishably, as "agreements of two or more owners of different items of intellectual property to license one another or third parties" (p. 28). In more precise terms, in an address before the American Intellectual Property Law Association, Klein (1997) defines cross-licensing as "an interchange of intellectual property rights between two or more persons", and patent pools as "an aggregation of intellectual property rights which are the subject of cross-licensing, whether they are transferred directly by patentee to licensee or through some medium, such as a joint venture, set up specifically to administer the patent pool" (p. 2, ftn 3). This distinction between cross-licensing agreements and patent pools also appears in Shapiro (2001).

${ }^{2}$ The U.S. history of patent pools started in 1856 with the sewing-machine pool. The assessment of patent pools under antitrust law has changed dramatically over time. These past changes are well documented by legal scholars, who interpret them as a consequence of a fundamental opposition between patent laws (which protect inventors from competition in the sale of goods covered by patents), and antitrust laws (which promote competition). On this see Andewelt (1984) and Kaplow (1984). For other detailed comments that consider the most recent cases of pool formation in high technology sectors, see Merges (1999) and Newberg (2000). For thorough economic analyzes of the history of patent pools under antitrust laws, see Carlson (1999) and Gilbert (2002). The European context is also discussed in Colangelo (2004) and Gilbert (2004).

${ }^{3}$ The patents that cover two innovations are complementary if both innovations are required to produce a given output. License agreements induce transaction costs as patentees and licensees use resources to identify relevant patents, negotiate royalties, or enforce property rights. A patent is blocking another patent if the latter may not be practiced without using the former. A patent infringement occurs when a patent is used in the absence of authorization by the patent holder.
} 
We can identify two possible research viewpoints on questions concerning patent pooling, namely the ex ante perspective and the ex post perspective.

We adopt the ex ante perspective to identify the basic trade-offs that determine the dynamic incentives to perform R\&D. Our starting point is that firms consider the possibility of participating in a patent pool in their private valuation of $R \& D$ programs. The pooling of patents allows the firms to coordinate their licensing behavior and increases their return on investment. This has an impact on their investment decisions provided firms are rational enough to anticipate the formation of the pool.

Although legal scholars and business practitioners have documented particularities of all kinds in clinical analyzes of patent pools, a few stylized features characterize recent arrangements: ${ }^{4}(i)$ they are based on an industry standard which has been designed at the industry level in advance of the formation of the pool; ${ }^{5}(i i)$ they form at the issue of a voluntary process in which patentees request a clearance statement from the regulator by submitting a pool proposal; ${ }^{6}$ (iii) they establish a mechanism for dividing among patentees the royalty stream; ${ }^{7}$ (iv)

\footnotetext{
${ }^{4}$ See Merges (1999) for a detailed description of the many organizational forms and contractual provisions of past and current pooling arrangements.

${ }^{5}$ Kulbaski (2002) documents the idea that the preliminary delineation of a standard constitutes a technologically grounded device for the determination of the patents to be subsequently included in a pool. Examples include the second Moving Picture Experts Group (MPEG-2) pool, which was formed in 1997, following a proposition to the DoJ by eight electronics firms and Columbia University. It concerned a video data storage compression standard established in 1994. The first Digital Versatile Discs (DVD) pool was cleared in 1998, and proposed by three firms. The second DVD pool was cleared in 1999, and proposed by six firms. The so-called DVD-3C and DVD-6C pools comply with the same two related standards for the production of digital supports and players that were defined in 1996. The 3rd Generation (3G) mobile patent pool was cleared in 2002, after a proposition issued by nineteen telecommunications companies. It is based on a standard defined in 1999. In the absence of standard, the formation of patent pools is more controversial, as exemplified by the current debate concerning their development in the biotechnology industry. See Grassler and Capria (2003) for arguments in favour of pools and Seide, and Lecointe and Granovsky (2001) for arguments against their use, in this sector.

${ }^{6}$ On this see the four U.S. Department of Justice Business Review Letters (1997, 1998, 1999 and 2002, available at: www.usdoj.gov/atr/public/busreview/1170.htm) regarding MPEG-2, the two DVD pools, and the $3 \mathrm{G}$ platform, respectively.

${ }^{7}$ For example, in the MPEG-2 case, the pool initiators licensed their patents to MPEG LA, a licensing agent. This separate entity offers the portfolio of patents as a package to third parties (although any particular patent may be licensed from a pool member individually). Royalties are then distributed according to a formula which reflects the respective weight of patent contributors to the pool. On this see Merges (1999, p. 28-31).
} 
they evolve over time to incorporate the innovations that are patented after pool creation. ${ }^{8}$

We develop a tractable dynamic model of pool formation that incorporates these features and study some of the consequences of the pool formation mechanism on the speed of innovation.

By contrast, the ex post perspective follows antitrust practices for reviewing the impact of a pool on welfare after the formation of that pool. The objective is then to identify what kind of pools should be authorized by the regulator, a question that is examined by Shapiro (2001). In this pioneering contribution, a very simple model lends theoretical support to the prevalent view that welfare is harmed when patents are perfect substitutes, and raised when patents are perfect complements. However, it is not always obvious that given patents are substitutes or complements. In that case, a relevant objective is to provide the regulator with some means to discriminate among pool candidates. Lerner and Tirole (2003) address this problem in a model that describes the full range between the extreme cases of perfectly substitutable and perfectly complementary patents. In this more general context, they notably show that the requirement that independent licenses be offered by pool members to third parties can be used as a screening device. The reason is roughly that independent licensing is innocuous when patents are complements, but reduces the pool's profit when patents are substitutes. Compulsory independent licensing thus lowers the incentive to pooling substitutable patents. In a companion paper, Lerner, Strojwas, and Tirole (2003) obtain empirical findings that are consistent with this theoretical result. Brenner (2004) extends the Lerner-Tirole setup to include a static (i.e. post innovation) modelling of the non-cooperative process of pool formation.

\footnotetext{
${ }^{8}$ The United States Patent and Trademark Office (2000) documents the fact that, in recent cases, the Department of Justice has not only focused on the complementary nature of existing patents to be licensed at the date of pool formation, but also required that participants license to each other complementary patents "they obtain in the future" (p. 7, original emphasis). Moreover, new patents in the pool do not necessarily originate from the pool initiators. For example, after 1997, the MPEG-2 pool grew by including additional patents from a set of firms which did not participate in the foundation of the pool, including France Telecom, Hitachi, and JVC.
} 
In other words, the problem of interest in the ex post perspective is to assess the potential impact of a proposed arrangement among patent holders on the functioning of the market in subsequent periods. The objective is to clear pools that will not raise more antitrust concerns than in the absence of pool. By contrast, what is at stake in the ex ante perspective is the magnitude of firms' incentives to invest in $\mathrm{R} \& \mathrm{D}$ as enhanced by the looming possibility to participate in the formation of a pool. A central issue thus consists in identifying the forces at work in a patent pool review process.

We believe that an ex ante perspective for analyzing patent pools is important because it takes into account the specific nature of patents. Unlike standard goods, patents exist for their incentive properties. Every manipulation of the value of patents has an impact on these properties and may change substantially the usefulness of patents as a means to encourage R\&D. In our analysis, we evacuate the antitrust concerns of all kinds by assuming that potential requirements by the antitrust authority are satisfied. We assume that all patents are complementary, pool members may license their inventions separately, and new patents may integrate the pool. ${ }^{9}$ We also limit the potential strategic externalities to concentrate on the profit enhancing property of pools. The value of a patent in a pool is supposed not to depend on the size of the pool. Similarly, the value of a patent outside the pool is supposed not to depend on the existence nor on the size of the pool. This allows us to analyze the impact of the formation of a pool, as well as the impact of the date of formation of this pool, on the speed of innovation.

We find that, compared to the situation where there is no possible pooling, the perspective of a pool enhances the speed of R\&D. More interestingly, we show that because firms value more

\footnotetext{
${ }^{9}$ These features were identified by considering four recent Departement of Justice Business Review Letters, that reveal antitrust enforcement intentions with respect to the formation of particular arrangements, namely the MPEG and two DVD pools in the information technology industry, and the 3G partnership in the mobile phone industry. The letters are responses to pool initiators which request a statement of the Department of Justice's antitrust enforcement intentions.
} 
being among the initial contributors to the pool - as opposed to innovating after the formation of the pool and then negotiating entry - the equilibrium pattern of innovative efforts is upward sloping before the formation of the pool. Eventually, we study the impact of the timing of the regulator's review process of patent proposals on the level of R\&D efforts and resulting welfare. This is done by describing the pool review as a sequential process in which the industry first proposes a set of patents, to which the regulator responds either by accepting the proposition or by imposing another set of patents. We find that this process may induce overinvestment in early innovations from the industry's point of view. It may also induce inefficiencies according to a social welfare criterion in the sense that the equilibrium number of patents generally falls short of the welfare maximization value.

Our analysis of patent pooling bears some resemblance with the standard literature on the ex ante study of patenting as exemplified by Reinganum (1989) or Grossman and Shapiro (1987) for instance. In both settings, incentives to innovate are provided by a "prize" in case of success. However, whereas the monopoly power associated to a patent is costly to the regulator, the formation of a patent pool can be beneficial even from a purely ex post point of view because it facilitates the diffusion of the innovations. This difference has some consequences for welfare analysis.

The paper is organized as follows. Section 2 builds a model of pool formation in the terms of a differential game. Section 3 offers a characterization of the Symmetric Markov Perfect Equilibria of the game. Section 4 is an analysis of the impact of the size of the pool on the incentives to invest in $R \& D$ and on the speed of innovation. Section 5 compares the equilibrium $R \& D$ investment choices with joint profit-maximizing levels and discusses the welfare implications of the pool review process. Section 6 is a conclusion. All proofs can be found in the Appendix. 


\section{The Patent Race Game}

We consider an industry of $N$ of symmetric firms. Each of them can obtain exactly one innovation by investing in a specific R\&D program. When it innovates, a firm is granted a patent of infinite length and thereby can secure a given flow of profit $\underline{v}$ (say, by licensing the innovation), which does not depend on the existence of other patents nor on their inclusion in a pool. Investment in an $R \& D$ program is a continuous time profit-maximization decision problem. At each point in time, each firm $i$ can decide independently to exert a non-negative $\mathrm{R} \& \mathrm{D}$ effort $x_{t}^{i}$ at some cost $c\left(x_{t}^{i}\right)$, which is such that $c(0)=0, c^{\prime}\left(x_{t}^{i}\right)>0$, and $c^{\prime \prime}\left(x_{t}^{i}\right)>0$. We also assume that $c^{\prime}(0)=0$ and $c^{\prime}(+\infty)=+\infty$, for a firm's optimal choice of effort to be an interior solution of the corresponding program. Innovation is described by a Poisson process and $x_{t}^{i}$ is normalized to be firm $i$ 's instantaneous probability of success. ${ }^{10}$

We denote by $K<N$ the minimal number of $\mathrm{R} \& \mathrm{D}$ programs that were identified, in a previous period, and at the industry level, as sources of complementary innovations which, taken together, can constitute a pool candidate. It can be the outcome of all kinds of considerations, in which technological determinants have some role. ${ }^{11}$ Henceforth we shall refer to $K$ as the initial pool size. This initial size of the pool is the one anticipated by all firms in the industry and results from the equilibrium of a sequential game between the industry and the relevant antitrust authority. We shall assume that $K$ is a parameter and postpone to section 5 the analysis of its determination.

\footnotetext{
${ }^{10}$ The Poisson assumption implies that there is no accumulation of knowledge, see Reinganum (1989).

${ }^{11}$ The role of technological specifications or constraints is likely to be prominent in the construction of pools which are based on an industry standard. Most patent pools currently in existence fall in this category, including MPEG-2, the two DVD proposals, and 3G. For a detailed and recent account of technological determinants in the formation of patent pools, see Gilbert (2002).
} 
When a pool forms, the flow of profit is denoted by $\bar{v}$ if the patent is in the pool, with

$$
\underline{v} \leq \bar{v}
$$

This inequality says that a pool increases the private value of the patents (say, because it coordinates the diffusion of a standard). ${ }^{12}$ Patent pooling is a cooperative agreement, which establishes the rules according to which pool profits are shared among individual firms. We assume that, once the pool is created, it has full bargaining power when it negotiates with potential entrants, and that all resulting profits are shared equally among pool initiators. As the pool cannot commit to reward new inventors more than their reservation profit, a firm that contemplates integrating an existing pool can only expect a flow of profit $\underline{v}$ from its patent. The important qualitative feature we want to capture through the latter specification is that a patentee would rather be in the set of pool initiators than become an incremental contributor obliged to negotiate its entry in an existing pool. ${ }^{13}$

These simplifying assumptions are made to keep the model tractable and nevertheless allow us to study the dynamic incentives to perform R\&D. To do that, in the following paragraphs we first examine the no-pool benchmark case. Then we establish the actualized value of the patents owned by the pool initiators and by outsiders, before describing a recursive formulation of the race to pool creation.

The No-Pool Benchmark Case Suppose that no patent pool may be formed. Since R\&D programs are independent of one another, the environment is non-strategic and we can analyze any firm's decision by studying the optimal pattern of investment for a single representative

\footnotetext{
${ }^{12}$ Note that $\underline{v}$ and $\bar{v}$ do not to depend on the size of the pool. However, as we shall see, the actualized value of participating in a pool does depend on $N$ and $K$.

${ }^{13}$ For a formal analysis of situations in which a firm finds it profitable not to join an existing pool, see Aoki and Nagaoka (2004).
} 
firm. The maximum value function $V$ of the firm's program depends on the innovation state, which can take values 0 or 1 . In case of success, or state 1 , the actualized value of a patent is $V(1)=\underline{v} / r$, where $r$ is the common interest rate. In the absence of innovation, or state 0 , the actualized value $V(0)$ of the firm's $R \& D$ program verifies

$$
r V(0)=\max _{x}[x(V(1)-V(0))-c(x)]
$$

In the usual terminology, the latter Bellman equation says that the return $r$ on the "asset" $V(0)$ is equal to the expected "capital gains" $x(V(1)-V(0))$ minus the flow of "dividends" $c(x)$. The first-order condition for an optimal level of effort implies that

$$
V(0)=\underline{v} / r-c^{\prime}(\underline{x})
$$

where $\underline{x}$ is solution to

$$
\underline{v}-(\underline{x}+r) c^{\prime}(\underline{x})+c(\underline{x})=0
$$

as obtained by plugging (3) into (2).

The Formation of the Pool Suppose that a patent pool may be formed by $K$ patents. Then the pool initiators are the $K$ first patentees, which thereby gain two kinds of benefits. First, they make a higher return on their own patent, that is $\bar{v}$, than in the benchmark case. In addition, they extract some rent, that is a flow of profit $\bar{v}-\underline{v}$, from any subsequent innovator interested in entering the pool. If we denote by $V_{K}(1)$ the actualized value of being entitled with a patent at the date of pool formation, we have

$$
V_{K}(1)=\frac{\bar{v}}{r}+\frac{N-K}{K} \frac{\underline{x}}{\underline{x}+r} \frac{\bar{v}-\underline{v}}{r} .
$$

The interpretation of the right-hand side of (5) is rather simple. The first term is the actualized value of a patent that forms the pool and brings a flow of profit equal to $\bar{v}$. The second term 
reflects the fact that each of the potential $N-K$ subsequent entrants contributes to the total pool value by a flow of rent equal to $\bar{v}-\underline{v}$. The total flow is actualized (divided by $r$ ), discounted by the "adjusted probability" of success of the R\&D programs $\frac{\underline{x}}{\underline{x}+r}$, and equally divided among the $K$ pool initiators. ${ }^{14}$ Remark that, after the formation of the pool, the R\&D decisions of all outsiders - the firms which have not patented yet and thus do not participate in the pool - are the same as in the no-pool benchmark case. Each of them invests $\underline{x}$, that is the solution to (4), and the actualized value of each $R \& D$ program is as displayed in (3), that is

$$
V_{K+1}(0)=\underline{v} / r-c^{\prime}(\underline{x})
$$

In other words, (6) is the value of not being among the $K$ first patent holders.

A Recursive Formulation of the Race to the Pool We now concentrate on the period starting at date 0 and finishing with the formation of the pool. This period is analogous to a race in which the prize consists in being among the $K$ first innovators, as this gives access to a portion of the pool value. Equivalently, we choose to describe it hereafter as a series of $K$ successive patent races. The environment is now strategic because each firm's expected return from a patent depends on the achievement of other firms to be among the $K$ first patentees, and thus on their respective investments. This implies that the maximum value of a firm's R\&D program is function not only of the innovation state (i.e., to be successful of not), but also of the existence of a subset of firms which patented an innovation. As we assume that choices in $R \& D$ investments depend only on a current value relevant state, and firms are identical,

\footnotetext{
${ }^{14}$ When the length of one period goes to infinity, the probability of success of the R\&D program goes to 1. However, time is costly and from the expected profit expression we can derive an "adjusted probability" of success. Suppose that the stationary investment of the firm is $x$ and the size of the reward in case of success is $\Pi$. Then the firm's expected profit is

$$
\pi=\int_{0}^{+\infty} x e^{-x t} e^{-r t} \Pi d t=\frac{x}{x+r} \Pi .
$$

In words, everything happens as if by investing $x$ the firm were instantaneously successful with probability $\frac{x}{x+r}$.
} 
we restrict attention to Symmetric Markov Perfect Equilibria. Note that symmetry makes the identity of race participants irrelevant for the expression of gains in any state. Value functions can thus be indexed only by the number of firms that have already patented an innovation or, equivalently, by the rank $k$ of the patent race in which a firm participates, with $k \leq N$. Formally, by generalizing previous notation, we denote by $V_{k}(0)$ the actualized value of a research program that aims at discovering the $k$-th innovation (when there exist $k-1$ patentees), and by $V_{k}(1)$ the actualized value of patenting in the $k$-th race (in which case there are $k$ patentees).

When exactly $k-1$ firms have patented an innovation, $N-k+1$ other firms keep investing in an $\mathrm{R} \& \mathrm{D}$ program. Let us concentrate on one of these firms, we label $i$, in order to compute its equilibrium strategy $x^{i}$. Firm $i$ 's R\&D program can either be successful before others and thus lead to an innovation of value $V_{k}(1)$, or fail in patenting the $k$-th innovation and be valued $V_{k+1}(0) .{ }^{15}$ It follows that the actualized value $V_{k}(0)$ of firm $i$ 's R\&D program of rank $k$ verifies

$$
r V_{k}(0)=\max _{x}\left[x\left(V_{k}(1)-V_{k}(0)\right)+X^{j}\left(V_{k+1}(0)-V_{k}(0)\right)-c(x)\right]
$$

where $X^{j}$ is the sum of the instantaneous R\&D efforts made by all other participating firms $j \neq i$. In words, the latter displayed expression equates the return on the "asset" $V_{k}(0)$ to the expected "capital gains" minus "dividends". In contrast to the no-pool benchmark case, here capital gains can take two forms, depending on whether firm $i$ innovates first or another firm $j$ gets ahead. The first-order condition leads to firm $i$ 's optimal effort strategy

$$
x_{k}^{i}=\left(c^{\prime}\right)^{-1}\left(V_{k}(1)-V_{k}(0)\right) .
$$

Recalling that a firm can perform only one innovation, hence all patent holders stop investing,

\footnotetext{
${ }^{15}$ When a firm participates in some race $k$ and does not succeed in being the first to discover an innovation, it initiates a new R\&D program of rank $k+1$. Accordingly, the actualized value of a program that fails to patent the $k$-th innovation can be denote by $V_{k+1}(0)$. For $k=N$, we adopt the notational convention that $V_{N+1}(0)=0$.
} 
we use the symmetry assumption to write $x_{k}^{i}=x_{k}$ for all $i$ and then transform (7) into

$$
r V_{k}(0)=x_{k} c^{\prime}\left(x_{k}\right)+(N-k) x_{k}\left(V_{k+1}(0)-V_{k}(0)\right)-c\left(x_{k}\right)
$$

Finally, to characterize completely the value function associated with this game, we must compute the value of patenting in the $k$-th race, that is $V_{k}(1)$. This is done by observing that during the $k+1$-th race, that is in the period that follows the discovery of the $k$-th innovation, and before the discovery of another innovation, each of the $k$ patentees receives a flow of profit equal to $\underline{v}$. In the same period, the event that one of the "remaining" $N-k$ firms succeeds in

patenting an innovation can occur with an "adjusted probability" of success of $\frac{(N-k) x_{k+1}}{r+(N-k) x_{k+1}}$, in which case the actualized value of all patents at the issue of the race is equal to the value of innovating at rank $k+1$, that is $V_{k+1}(1)$. Otherwise, all $\mathrm{R} \& \mathrm{D}$ programs fail with probability $\frac{r}{r+(N-k) x_{k+1}}$, and the actualized value of each existing $k$ patents remains equal to $V_{k}(1)$. This leads to

$$
V_{k}(1)=\frac{r\left(\frac{v}{r}\right)+(N-k) x_{k+1} V_{k+1}(1)}{r+(N-k) x_{k+1}} .
$$

In other words, $V_{k}(1)$ is the value of a lottery, in which a firm can gain $\frac{\underline{v}}{r}$ with probability $\frac{r}{r+(N-k) x_{k+1}}$, or $V_{k+1}(1)$ with probability $\frac{(N-k) x_{k+1}}{r+(N-k) x_{k+1}}$.

\section{$3 \quad$ Equilibrium Pattern of R\&D Efforts}

In this section we characterize the Symmetric Markov Perfect Equilibria of the $K$ races. The two main properties we obtain in a first proposition are that equilibrium $R \& D$ efforts (as made by firms that have not innovated yet) are increasing with time as long as the pool is not formed, and are always greater than the post pool-formation efforts. These basic properties are obtained through a series of lemmas which characterize the solution(s) of the recursive system as formulated above. 
Lemma 1 For all $k<K-1$, we have:

$$
\frac{\underline{v}}{r}<V_{k}(1)<V_{k+1}(1) .
$$

This says that the value of a patent increases as the rank $k$ gets closer to the pool formation rank $K$. Indeed, the reward accruing to a patentee which participates in the formation of the pool is less discounted in race $k+1$ than at rank $k$. Moreover, since owning one of the $K$ first patents gives access to a share of the pool's profits on top of the flow of profits obtained in the no pool situation, we have $V_{k}(1)>\frac{v}{r}$.

Lemma 2 After the formation of the pool, outsiders' RËD efforts decrease:

$$
x_{K}>\underline{x} .
$$

This claim becomes intuitive if one observes that, in the $K$-th patent race, firms have a last chance to participate in the formation of the pool. This perspective encourages them to choose a more aggressive strategy than in the absence of hope to benefit from the pool's profits. Exacerbated competition in this last race induces a higher effort level than in the post pool-formation period. The next lemma establishes the monotonicity of equilibrium investment efforts.

Lemma 3 The two following properties are equivalent:

(i) $x_{k}<x_{k+1}$;

(ii) $\underline{x}<x_{k}$. 
By combining the latter statement with Lemma 2, we can now state the main result of this section.

Proposition 1 Before the formation of the pool, race participants' REBD efforts increase with the rank of the race. After the formation of the pool, outsiders' REDD efforts decrease drastically. Formally, for all $k \leq K-1$, we have:

$$
\underline{x}<x_{k}<x_{k+1}
$$

The information this proposition gives on the equilibrium $R \& D$ effort levels of race participants is summarized in Figure 1.

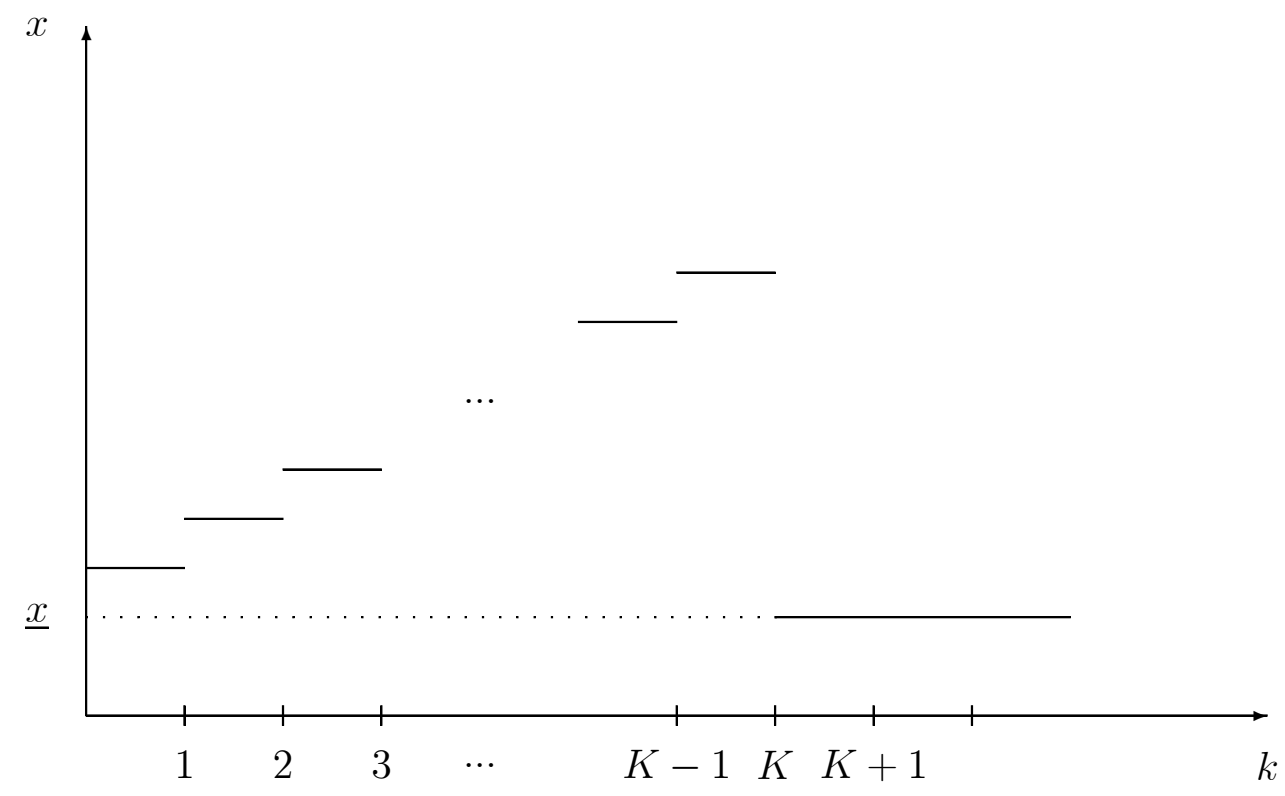

Figure 1: Pattern of Equilibrium R\&D Effort Levels. 
A clear implication of Proposition 1 is that the pooling of patents has a positive impact on R\&D activity. Compared to a situation in which no pool can be formed, the speed of innovation is higher before the formation of the pool (i.e., $x_{k}>\underline{x}$ ). By increasing the prospective profits of a patent, the pool acts as an additional reward, and thus enhances incentives to perform R\&D. This simple result confirms in a formal way the claim by Lerner and Tirole (2003) that "the prospect of a pool raises individual profit and thereby encourages innovation" (p. 27).

Another consequence of Proposition 1 is that, as the number of patents gets closer to the pool formation level, successive races become increasingly tougher, inducing the participants to raise their level of effort. This characterization is rooted in three distinct effects. First, in the $k$-th patent race, the number of participants is larger than in the $k+1$-th race. The access to the prize, which consists in being among the $K$ first innovators, is thus more hazardous at the lower rank, leading to weaker incentives to invest. Second, if a firm wins the $k$-th race, it waits longer for the formation of the pool than if it succeeds in patenting the $k+1$-th innovation. Time being discounted, the reward is thus smaller in the $k$-th race. Finally, the failure to innovate is less damaging in the $k$-th race than in the $k+1$-th race. The reason is that, at the lower rank, there is one more race to run before the formation of the pool, and thus one additional chance to be among the $K$ first patentees. All these effects contribute to obtaining that $x_{k}<x_{k+1}$.

Remark that we did not address so far the question of the uniqueness of the solution (8) to the recursive system. Actually, it is not clear that the Bellman equation (7) has only one solution, meaning that the differential game we consider may have several Symmetric Markov Perfect Equilibria. However, Proposition 1 was proved without relying on uniqueness. This means that our results are valid for all possible equilibria. In all equilibrium paths, race participants' R\&D efforts increase over time until pool formation. 
We end this section with a lemma that will be useful for subsequent analysis.

Lemma 4 For all $k \leq K$, we have:

$$
V_{k}(0)>V_{K+1}(0)=\frac{\underline{v}}{r}-c^{\prime}(\underline{x}) .
$$

In more intuitive terms, this lemma says that the perspective of the formation of a pool increases the potential value of an innovation, and thus also increases the value of all research programs.

\section{Size Effects}

We already know from Proposition 1 that the mere possibility of forming a pool increases the speed of innovation. In this section we want to analyze the impact of the size of the pool, $K$, on the incentives to invest in $\mathrm{R} \& \mathrm{D}$, and thus on the speed of innovation. Because the perspective of a pool acts as a reward on investment, increasing the pool size from $\underline{K}$ to $\bar{K}$ should a priori raise effort levels that aim at patenting in races $\underline{K}$ to $\bar{K}$, all other things remaining equal. We will see with Proposition 2 that this is not the only impact of an increased pool size, since this also results in a reduction of efforts in the $\underline{K}$ first races.

As the proof of the results below make use of the uniqueness of the equilibrium solution to the recursive system, we start by identifying the following mild sufficient condition.

Lemma 5 If $c^{\prime \prime \prime} \geq 0$, then the differential game has only one Symmetric Markov Perfect Equilibrium.

From now on, we introduce the additional assumption that $c^{\prime \prime \prime} \geq 0$. 
Because we want to compare the Symmetric Markov Perfect Equilibrium for different values of the pool size, we extend the previous notation by explicitly incorporating $K$ in the arguments of the value function and the effort level. We now denote by $V_{k}(1, K)\left(\operatorname{resp} . V_{k}(0, K)\right)$ the value associated with a patent (resp. a research program) when exactly $k$ innovations (resp. exactly $k-1$ innovations) have been patented, and $K$ patents are needed to form a pool. The corresponding effort level of the firms which participate in the $k$-th patent race is $x_{k}(K)$.

Lemma $6 V_{K}(1, K)$ is a strictly decreasing function of $K$.

This claim is derived directly from equation (5), and results from the fact that the value of participating in the formation of the pool gets lower if the size $K$ increases, since the benefits will be reduced - there will be less potential entrants from which to extract a rent - and will be shared by a larger number of insiders.

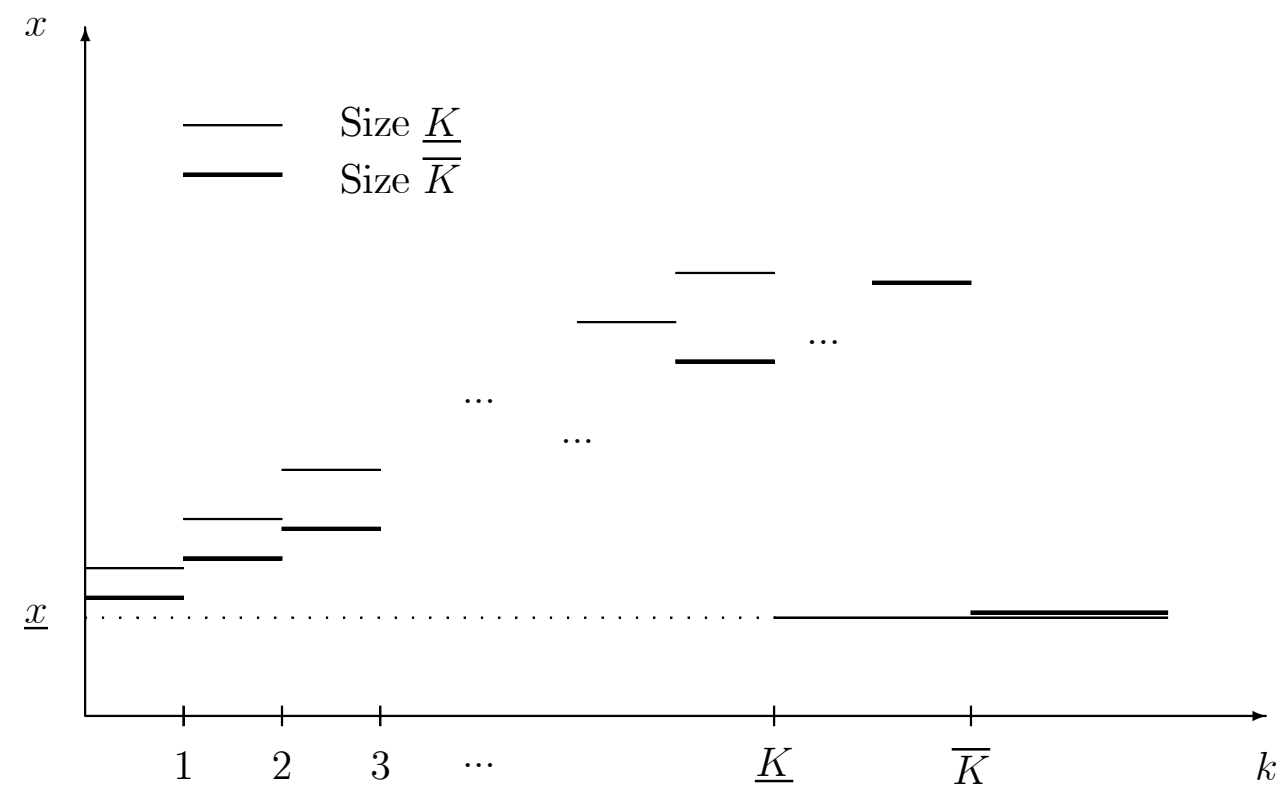


Figure 2: Comparing Two Pool Sizes.

Proposition 2 For two different pool sizes, $\underline{K}<\bar{K}$, the equilibrium patterns of innovative effort levels verify:

(i) for $k \leq \underline{K}, x_{k}(\underline{K})>x_{k}(\bar{K})$;

(ii) for $k>\bar{K}, x_{k}(\bar{K})=x_{k}(\underline{K})=\underline{x}$;

(iii) for $\underline{K}<k \leq \bar{K}, x_{k}(\bar{K})>\underline{x}=x_{k}(\underline{K})$;

(iv) $x_{\underline{K}}(\underline{K})>x_{\bar{K}}(\bar{K})$.

In words, this proposition offers a complete comparison of equilibrium R\&D effort patterns as obtained in the small and large pool cases: (i) establishes that race participants' R\&D efforts at each rank $k$ in the small size case are higher than in the large size case; (ii) states that the post pool-formation R\&D efforts of outsiders fall at the no-pool optimal level $\underline{x}$ for all pool sizes (whereas pool initiators do not invest anymore); eventually, an increase in pool size implies a prolongation of race participants' equilibrium $\mathrm{R} \& \mathrm{D}$ efforts, which according to $(i i i)$ are above the no-pool optimal level, and from (iv) are below the final race level of a smaller sized pool. All results given in Proposition 2 are summarized in Figure 2.

An interesting implication of Proposition 2 is that increasing the minimum size of the pool dilutes the incentives to obtain the first patents, and thus decreases the equilibrium R\&D efforts for the discovery of innovations. This important effect is the consequence of three distinct factors. First, patenting in the $k$-th race is more valuable if $K$ is smaller because the discount applied on the reward is smaller (the waiting time is shorter). Second, the reward itself is higher for a smaller $K$ because the pool's profit pie is not only larger but also divided among a smaller set of firms. Finally, the larger $K$, the less damaging a failure in the $k$-th race, since the number 
of opportunities to belong to the set of pool initiators (that is, the number of subsequent races $K-k)$, as faced by an unsuccessful firm, increases with the minimum size of the pool. All three factors contribute to the claim that, although unsuccessful firms have an incentive to increase their R\&D effort successively from the first to the $K$-th race, a reduction in the size of the pool implies higher levels of investment in each race.

\section{Pre Pool-Formation Incentives and Welfare Consequences}

We can now use the results obtained in the previous sections to point to two distinct sources of distortions. The first one affects private benefits and originates from the pre pool-formation incentives, which drive firms' R\&D investment decisions. The second one impacts social welfare and is rooted in the prospective orientation of the pool review process, as conducted by the regulator.

Early Overinvestment in Innovation Consider for one moment the overall industry acting as a single player and assume that this player has control over the rank $K$ and the vector $\mathbf{x}=\left(x_{1}, x_{2}, \ldots, x_{N}\right)$ of investment levels chosen by all firms. This player will maximize the joint profits of the innovative firms. As the effect of the pool formation is to increase the value of the innovations (from $\underline{v}$ to $\bar{v}$ ), a simple revealed preference argument leads to the conclusion that it cannot be worse off by choosing $K=1$ than any other pool size. ${ }^{16}$ The profit accruing to the industry for each innovation is then $\bar{v} / r$ and the optimal investment level in each project is then $\bar{x}$ such that $\bar{v}-(\bar{x}+r) c^{\prime}(\bar{x})+c(\bar{x})=0$. As $c($.$) is convex and \bar{v} \geq \underline{v}$, we have $\bar{x} \geq \underline{x}$. This investment level is also the one chosen independently by firms involved in an R\&D program with

\footnotetext{
${ }^{16}$ The fact that one patent is sufficient to form a pool is one of our modelling assumptions and may be surprising. Actually, one can consider that two (or more) patents are needed to form a pool, it will not challenge the validity of the point made here but will only add computational complexity.
} 
expected return $\bar{v}$, as demonstrated in Section 2. We refer to the choice $K=1$ and the levels $\overline{\mathbf{x}}=(\bar{x}, \ldots, \bar{x})$ as the joint profit-maximizing strategy of the industry. By using this optimal strategy as a benchmark for the assessment of firms' behavior, we reach the conclusion that a pool formation process induces firms to overinvest in early innovations. This occurs because, in our model, being among the pool initiators is over-rewarded through the extraction of the rent from firms which innovate after the formation of the pool. In particular, recall that the private value of the $K$-th innovator is $V(1, K)=\frac{\bar{\nu}}{r}+\frac{N-K}{K} \frac{\underline{x}}{\underline{x}+r} \frac{(\bar{\nu}-\underline{\nu})}{r}$, which is strictly greater than $\bar{v} / r$ for all $K<N$. We obtain the following result:

Proposition 3 The race to the patent pool exhibits overinvestment in innovation compared to the joint profit-maximizing R\&D levels. Formally, for all $K<N$, we have:

$$
x_{K}(K)>\bar{x}
$$

It is interesting to link this proposition to the research contributions on multi-stage patent races which concentrate on the cumulative nature of innovation. This literature is mainly concerned by the problem of rewarding the early inventors for opening the way to subsequent improvements, and generally insists on the insufficient incentives given by patent protection. (See Green and Scotchmer (1995), Chang (1995) or Matutes, Régibeau and Rockett (1996) for representative contributions.) We find that a patent pool can be conceived as a means to increase the rewards to early inventors, so long as it enhances their bargaining power when time comes to negotiate the inclusion in the pool of new patents by subsequent innovators. The idea that firms may overinvest in $\mathrm{R} \& \mathrm{D}$ prior to the formation of the pool contrasts with the ex post antitrust concern that firms may free ride on other pool participants' discoveries, thereby leading to suboptimal 
R\&D investments. This may occur when a pool agreement stipulates the cross-licensing of present as well as future patents (see the Antitrust Guidelines for the Licensing of Intellectual Property (1995)).

Delayed Formation of the Pool From a social welfare point of view, the pool formation process may also entail some form of distortion. To see this point, let us consider a measure of the social welfare $S W=S W(\mathbf{x}, K)$. In equilibrium $\mathbf{x}=\mathbf{x}(K)$, so that the variable $K$ influences the measure of social welfare in two ways, directly through its impact on the social value of an innovation (this comes from the fact that the social value of an innovation may not be the same whether its corresponding patent is in a pool or not), and indirectly through its impact on the speed of the R\&D process (i.e. the levels of investment). We suppose that the basic problem of the regulator is to encourage $R \& D$ in situations characterized by the following property:

Property $\left.\mathbf{1} \frac{\partial S W}{\partial x_{i}}\right|_{\mathbf{x} \leq\left(x_{1}(1), x_{2}(2), \ldots, x_{N}(N)\right)}>0$, for any $i$.

When the latter property is verified, the function $S W$ is assumed to be increasing in $x_{i}$, on the domain relevant for our analysis, that is for all $R \& D$ investments that are lower than what is possibly chosen by any firm in equilibrium. In our model, this holds true as long as the social value associated with an innovation is greater than its value for each innovative firm.

The decision to clear or not the formation of a pool is taken by the competition authorities. In all recent cases, some negotiation process at the industry level has led to the delineation of the dimensions of a pool proposal based on a technological standard. In our notational context, this is captured by the selection of a rank $k$ at which clearance by the regulator is requested. Then the decision of the regulator to grant clearance to the proposed pool comes as a response. In this review process, the regulator can impose conditions (i.e., a new size $K \geq k$ ) for the pool 
proposal to be eventually cleared. ${ }^{17}$ From an ex ante perspective, in our model the socially optimal choice of $K$ by the regulator is captured by the maximization of $S W(\mathbf{x}(K), K)$. Then innovations patented after the formation of the pool, that is from $K+1$ onward, may be included in the pool.

Suppose first that the regulator is consulted by the patent holders at date 0 , that is when no innovation has yet been patented, and that the regulator performs a prospective analysis to obtain $\underline{K}$ as a solution to the welfare maximization problem. To compare, suppose now that the regulator is consulted after date 0 , that is when $k-1$ innovations have already been obtained with all firms anticipating the creation of a pool of $\underline{K}$ patents, with $1<k \leq \underline{K}$. Again, let the regulator perform a prospective analysis to select a pool size $K$ that maximizes the relevant social welfare function, which in this case writes $S W\left(x_{1}(\underline{K}), \ldots, x_{k-1}(\underline{K}), x_{k}(K), \ldots, x_{N}(K), K\right)$. If social welfare increases in each firm's R\&D investment, this may result in a rise in the minimum pool size, that is in a choice of $\bar{K}>\underline{K}$. In that case, if firms are sufficiently rational to anticipate accurately the formation of the pool, we obtain that $\underline{K}$ cannot be anticipated by firms. ${ }^{18}$ This reasoning is grounded on the following formal result:

Proposition 4 If Property 1 is verified, for all $k<\underline{K}<\bar{K}$, we have:

$$
S W(\mathbf{x}(\bar{K}), \bar{K})<S W\left(x_{1}(\underline{K}), \ldots, x_{k-1}(\underline{K}), x_{k}(\bar{K}), \ldots, x_{N}(\bar{K}), \bar{K}\right) .
$$

In words, the latter inequality says that the (expectation taken at date 0 of the) social welfare corresponding to a choice $K=\bar{K}$ is lower than the (expectation taken at date 0 of the) social

\footnotetext{
${ }^{17}$ Recall that in our ex ante approach we evacuate the antitrust concerns about patent substitutability. Our complementarity assumption implies that it is suboptimal for the regulator to exclude patents from the pool.

${ }^{18}$ Arguably, the detailed treatment of past cases, as offered by the DoJ Business Review Letters, together with the related comments by business consultants and lawyers offer sufficient guidance for firms to anticipate the outcome of a pool review process from the outset (for recent examples, see Morse (2002) or Lind et al. (2003)).
} 
welfare obtained if firms anticipate $K=\underline{K}$ during the first $k-1$ races before realizing that $K=\bar{K}$. This claim is a direct consequence of Proposition 2 (recall that $x_{k}(\bar{K})<x_{k}(\underline{K})$ for all $k \leq \underline{K}<\bar{K}$ ) and Property 1 . In intuitive terms, it says that if the acceptance/refusal decision concerning a pool proposal is made on a purely prospective basis at date $k$, it overlooks the pre pool formation incentive properties that drive firms' choices of R\&D investments. As a consequence, even if $S W(\mathbf{x}(\bar{K}), \bar{K})<S W(\mathbf{x}(\underline{K}), \underline{K})$, it may be the case that from $k$ onward $\bar{K}$ turns out to be the regulator's best choice. This in turn restricts from below the range of sizes $K$ that can be anticipated by the pool candidates. As more time is needed to obtain a larger number of patents, this will tend to delay the acceptance decision more than what would be optimal from an ex ante perspective. The chosen $\bar{K}$ may be larger than the $K$ that maximizes $S W(\mathbf{x}(K), K) \cdot{ }^{19}$

This result is consistent with the standard analysis of patents. In the more common situation of single patent attribution as well, the regulator has fewer motives to award a monopoly power to an innovator ex post than in the pre innovation period, in which the necessary incentives to perform $\mathrm{R} \& \mathrm{D}$ are taken into account. However, the case of patent pools is more subtle, since some of their virtues (to coordinate the launch of a standard, to clear blocking positions, to reduce transaction costs, to avoid costly infringement litigation), beyond the exercise of monopoly power, can yield benefits to society also ex post. Consequently, the regulator will not waver between the options to clear or not to clear the pool, but rather between the options to clear it now or to clear it later.

\footnotetext{
${ }^{19}$ The business professional literature offers anecdotal evidence that a pool review is a timely process. For example, the $3 \mathrm{G}$ pool is based on a standard defined in 1999, but was given clearance in 2002. Swidler Berlin Shereff Friedman LLP (2003) argue that the pool review process "moved at a glacial pace", and that "the parties' interests were harmed by having to wait three years to get a sign-off from the DoJ" (p. 4).
} 


\section{Conclusion}

Previous contributions to the emerging IO literature on patent pools have followed antitrust practice in adopting the ex post perspective for reviewing pool proposals. We have adopted the ex ante viewpoint to build a tractable dynamic model of multi-stage innovation, leading to the formation of a pool, and which captures well documented stylized features. The pre poolformation situation is described as a series of successive patent races leading to a prize, which consists in founding the pool, and thereby in gaining access to a portion of the pool value. After the formation of the pool, late innovators can integrate the pool only by negotiating entry with the pool initiators.

As a result, the pooling of patents appears to have a positive impact on $\mathrm{R} \& \mathrm{D}$ activity, in the sense that the speed of innovation is higher before the formation of the pool than compared to a situation in which no pool can be formed. More precisely, as the number of patents gets closer to the anticipated pool formation size, it is found that pool candidates raise their level of effort. A firm's investment pattern is thus upward sloping over time before pool formation, and decreases afterwards.

The analysis offers also a complete comparison of equilibrium R\&D effort patterns for two different sizes of patent pools. The main insights are as follows: for a given rank in the innovation series leading to the pool, a race participants' $R \& D$ investment is higher in the small pool size case than in the large size case; the post pool-formation $R \& D$ investment of outsiders falls at the no-pool optimal level for all pool sizes; eventually, an increase in pool size implies a prolongation of race participants' equilibrium $R \& D$ investment below the final race level of a smaller sized pool but above the no-pool optimal level. These results imply that an increase in the number of innovations which are required to form a pool dilutes firms' incentives to obtain the first patents, 
and thus decreases the equilibrium $R \& D$ investments.

Eventually, our analysis points to two separate sources of distortions. They originate from the characterization of private incentives as faced by firms in the pre pool-formation race, and from the prospective nature of the pool review process as conducted by the regulator. First, we argue that, if the firms which innovate after the formation of the pool are not protected enough against rent extraction by the pool initiators, then an overinvestment in R\&D may occur before the formation of the pool, followed by an underinvestment in all successive periods. This complements the antitrust concern that, in the post pool-formation period, firms may produce too little innovation effort by free riding on other pool participants' discoveries. Moreover, we obtain that a cost-benefit analysis, as performed by a forward looking regulatory authority, overlooks the incentive properties of participating in the foundation of a pool, and thus overestimates the gains of delaying the formation of pools, a source of inefficiency. 


\section{Appendix}

\subsection{Proofs}

Proof of Lemma 1 The proof is immediate since we know from (5) that $V_{K}(1)>\frac{\underline{v}}{r}$, and from (10) that $V_{k}(1)$ is a convex combination of $\frac{v}{r}$ and $V_{k+1}(1)$.

Proof of Lemma 2 To prove this lemma, remark first that the function $\underline{v}-r c^{\prime}(x)+c(x)-$ $x c^{\prime}(x)$ takes the value 0 at $\underline{x}$ and is decreasing in $x$ (because $c$ is convex). From (6),(8) and (9) we can write

$$
r\left[V_{K}(1)-c^{\prime}\left(x_{K}\right)\right]=-c\left(x_{K}\right)+x_{K} c^{\prime}\left(x_{K}\right)+(N-K) x_{K}\left[\frac{\underline{v}}{r}-c^{\prime}(\underline{x})-V_{K}(1)+c^{\prime}\left(x_{K}\right)\right],
$$

which is equivalent to

$$
r\left[V_{K}(1)-\frac{\underline{v}}{r}\right]+\underline{v}+c\left(x_{K}\right)-\left(r+x_{K}\right) c^{\prime}\left(x_{K}\right)+(N-K) x_{K}\left[V_{K}(1)-\frac{\underline{v}}{r}+c^{\prime}(\underline{x})-c^{\prime}\left(x_{K}\right)\right]=0 .
$$

If we suppose that $x_{K}<\underline{x}$, then all the terms of this sum are (strictly) positive, which is impossible. Hence we must have $x_{K}>\underline{x}$.

Proof of Lemma 3 Let us start by proving that $x_{k+1}<x_{k}$ implies $x_{k}<\underline{x}$. By rewriting (9) using (8), we have

$$
r\left[V_{k}(1)-c^{\prime}\left(x_{k}\right)\right]=x_{k} c^{\prime}\left(x_{k}\right)+(N-k) x_{k}\left[V_{k+1}(1)-c^{\prime}\left(x_{k+1}\right)-V_{k}(1)+c^{\prime}\left(x_{k}\right)\right]-c\left(x_{k}\right) .
$$

Moreover, we know from (10) that

$$
-(N-k) x_{k+1}\left[V_{k+1}(1)-V_{k}(1)\right]+r V_{k}(1)=\underline{v},
$$

and Lemma 1 together with $x_{k+1}<x_{k}$ gives

$$
-(N-k) x_{k}\left[V_{k+1}(1)-V_{k}(1)\right]+c^{\prime}\left(x_{k}\right)-c^{\prime}\left(x_{k+1}\right)+r V_{k}(1)<\underline{v} .
$$


We can now rewrite (11) as

$$
\underline{v}-\left(r+x_{k}\right) c^{\prime}\left(x_{k}\right)+c\left(x_{k}\right)>0,
$$

which in turn implies $x_{k}<\underline{x}$. For the other implication, $x_{k}<\underline{x}$ implies that $-r c^{\prime}\left(x_{k}\right)+c\left(x_{k}\right)-$ $x_{k} c^{\prime}\left(x_{k}\right)>-\underline{v}=(N-k) x_{k+1}\left(V_{k+1}(1)-V_{k}(1)\right)-r V_{k}(1)$, thus from (11) we have

$$
(N-k)\left(x_{k+1}-x_{k}\right)\left[V_{k+1}(1)-V_{k}(1)\right]+(N-k) x_{k}\left[c^{\prime}\left(x_{k+1}\right)-c^{\prime}\left(x_{k}\right)\right]<0 .
$$

Then Lemma 1 implies that $x_{k+1}<x_{k}$ must be verified.

Proof of Lemma 4 Assume that the weak inequality is verified for $k+1$, and suppose that $V_{k}(0) \leq \frac{\underline{v}}{r}-c^{\prime}(\underline{x})$. Then from (9) we derive that $\underline{v}-r c^{\prime}(\underline{x}) \geq-c\left(x_{k}\right)+x_{k} c^{\prime}\left(x_{k}\right)$, which is impossible because $x_{k}>\underline{x}$. To conclude the proof, remark that the weak inequality is verified at $K+1$.

Proof of Lemma 5 Define the function

$$
F\left(x_{k}\right)=r V_{k}(1)-\left(r+x_{k}\right) c^{\prime}\left(x_{k}\right)+c\left(x_{k}\right)-(N-k) x_{k}\left[V_{k+1}(1)-c^{\prime}\left(x_{k+1}\right)-V_{k}(1)+c^{\prime}\left(x_{k}\right)\right] .
$$

From (10) we obtain $F(0)>0$, and if $c^{\prime \prime \prime} \geq 0$ then $F^{\prime \prime}<0$. Hence there exists only one $x_{k}$ such that $F\left(x_{k}\right)=0$ (which corresponds to a solution of the Bellman equation). By iterating, we demonstrate that there exists only one symmetric equilibrium path.

Proof of Proposition 2 The points (ii) and (iii) are straightforward. Let us prove point (i). Consider the case $K=\underline{K}$. We know from equation (10) that

$$
V_{k+1}(1, \underline{K})-V_{k}(1, \underline{K})=\frac{r\left(V_{k}(1, \underline{K})-\frac{\underline{v}}{r}\right)}{(N-k) x_{k+1}(\underline{K})}
$$


and replacing that into equation (11) gives

$$
\begin{aligned}
r\left[V_{k}(1, \underline{K})-c^{\prime}\left(x_{k}(\underline{K})\right)\right] & =-c\left(x_{k}(\underline{K})\right)+x_{k}(\underline{K}) c^{\prime}\left(x_{k}(\underline{K})\right) \\
+ & (N-k) x_{k}(\underline{K})\left[\frac{r\left(V_{k}(1, \underline{K})-\frac{\underline{v}}{r}\right)}{(N-k) x_{k+1}(\underline{K})}-c^{\prime}\left(x_{k+1}(\underline{K})\right)+c^{\prime}\left(x_{k}(\underline{K})\right)\right] .
\end{aligned}
$$

or equivalently

$$
\begin{aligned}
F\left(x_{k}(\underline{K}), \underline{K}\right)=r\left(1-\frac{x_{k}(\underline{K})}{x_{k+1}(\underline{K})}\right)\left(V_{k}(1, \underline{K})-\frac{\underline{v}}{r}\right)+\underline{v}+c\left(x_{k}(\underline{K})-x_{k}(\underline{K}) c^{\prime}\left(x_{k}(\underline{K})\right)\right. \\
-r c^{\prime}\left(x_{k}(\underline{K})\right)+(N-k) x_{k}(\underline{K})\left[c^{\prime}\left(x_{k+1}(\underline{K})\right)-c^{\prime}\left(x_{k}(\underline{K})\right)\right]=0 .
\end{aligned}
$$

Now suppose that at stage $k+1$ we have $V_{k+1}(1, \underline{K})>V_{k+1}(1, \bar{K})$ and $x_{k+1}(\underline{K})>x_{k+1}(\bar{K})$, where $\bar{K}>\underline{K}$. Then from equation (10) we deduce that $V_{k}(1, \underline{K})>V_{k}(1, \bar{K})$ because in the $\underline{K}$-case, we give more weight to the most valuable point in the convex combination and this most valuable point is more valuable than in the $\bar{K}$-case. From the definition of $F$, we also know that $F\left(x_{k}(\bar{K}), \bar{K}\right)=0$ and $F(0, \bar{K})>0$. Next, we can verify that because $x_{k+1}(\underline{K})>x_{k+1}(\bar{K})$, $x_{k+1}(\underline{K})>x_{k}(\underline{K})$ and $V_{k}(1, \underline{K})>V_{k}(1, \bar{K})>\frac{v}{r}$, we have $F\left(x_{k}(\underline{K}), \bar{K}\right)<0$. But then, the intermediate value theorem together with the unicity of the Symmetric Markov Perfect Equilibrium gives $x_{k}(\underline{K})>x_{k}(\bar{K})$. The only thing that remains to be proved now is that $V_{\underline{K}}(1, \underline{K})>V_{\underline{K}}(1, \bar{K})$ and $x_{\underline{K}}(\underline{K})>x_{\underline{K}}(\bar{K})$. The first point is a direct consequence of Lemma 1 and Lemma 6. For the second point it is useful to come back to the following expression

$$
F(x, K)=r V_{k}(1, K)-(r+x) c^{\prime}(x)+c(x)-(N-k) x\left[V_{k+1}(0, K)-V_{k}(1, K)+c^{\prime}(x)\right] .
$$

The function $F$ defined in this way verifies $F(0, K)>0, F\left(x_{k}(\underline{K}), \underline{K}\right)=F\left(x_{k}(\bar{K}), \bar{K}\right)=0$. Using the fact that $V_{\underline{K}}(1, \underline{K})>V_{\underline{K}}(1, \bar{K})$ and $V_{\underline{K}+1}(0, \underline{K})<V_{\underline{K}+1}(0, \bar{K})$ (which comes from Lemma 4), we can deduce that $F\left(x_{k}(\underline{K}), \bar{K}\right)<0$. Again, the intermediate value theorem together with the unicity of the Symmetric Markov Perfect Equilibrium gives $x_{\underline{K}}(\underline{K})>x_{\underline{K}}(\bar{K})$, as expected. 
Eventually, to prove $(i v)$, consider the function $F(x, K)=r V_{K}(1, K)-(r+x) c^{\prime}(x)+$ $c(x)-(N-K) x\left[V_{K+1}(0, K)-V_{K}(1, K)+c^{\prime}(x)\right]$. By definition $F\left(x_{K}(K), K\right)=0$ and we have $F(0, K)>0$. Consider $\bar{K}>K$, we know from Lemma 6 that $V_{K}(1, K)>V_{\bar{K}}(1, \bar{K})$. Moreover $V_{K+1}(0, K)=V_{\bar{K}+1}(0, \bar{K})$ and $V_{K+1}(0, K)-V_{K}(1, K)+c^{\prime}(x)<0$ (Lemma 4). Hence we have $F\left(x_{K}(K), \bar{K}\right)<0$. The intermediate value theorem together with the unicity of the Symmetric Markov Perfect Equilibrium gives $x_{\bar{K}}(\bar{K})<x_{K}(K)$. This concludes the proof.

Proof of Proposition 3 Suppose $x_{K} \leq \bar{x}$. We know that $x_{K}=\left(c^{\prime}\right)^{-1}\left(V_{K}(1, K)-\right.$ $\left.V_{K}(0, K)\right)$ and as $\left(c^{\prime}\right)^{-1}$ is increasing and $V_{K}(1, K) \leq \frac{\bar{v}}{r}$, this implies necessarily that $V_{K}(0, K) \geq$ $\frac{\bar{v}}{r}-c^{\prime}(\bar{x})$ or $r V_{K}(0, K) \geq \bar{x} c^{\prime}\left(\bar{x}-c(\bar{x})\right.$. The hypothesis $c^{\prime \prime}>0$ and the starting assumption $x_{K} \leq \bar{x}$ together give $V_{K}(0, K) \geq x_{K} c^{\prime}\left(x_{K}\right)-c\left(x_{K}\right)$. But this is inconsistent with equation (9) because $V_{K+1}(0, K)<V_{K}(0, K)$. Thus $x_{K}>\bar{x}$. 


\section{References}

Andewelt, R. B., 1984, "Analysis of Patent Pools under the Antitrust Laws," Antitrust Law Journal: 611.

Aoki, R. and S. Nagaoka, 2004, "The Consortium Standard and Patent Pools," Discussion Paper No. 32, Hitotsubashi University.

Brenner, S. 2004, "Stable Patent pools", Working Paper, Technical University of Munich.

Chang, H. F., 1995, "Patent Scope, Antitrust Policy and Cumulative Innovation," RAND Journal of Economics, 26(1): 34-57.

Colangelo, G., 2005, "Avoiding the Tragedy of the Anticommons: Collective Rights Organizations, Patent pools, and the Role of Antitrust," LE Lab Working Paper No. IP-01-2004, LUISS.

Denicolò, V., 2000, "Two-Stage Patent Races and Patent Policy," RAND Journal of Economics, 31(3): 488-501.

Fudenberg, D. and J. Tirole, 1991, Game Theory, MIT Press.

Gilbert, R., 2002, "Antitrust for Patent Pools: A Century of Policy Evolution," mimeo, University of California at Berkeley.

Gilbert, R., 2004, "Converging Doctrines? US and EU Antitrust Policy for the Licensing of Intellectual Property," Working Paper No. CPC04-44, University of California at Berkeley.

Grassler, F. and M. A. Capria, 2003, "Patent Pooling: Uncorking a Technology Transfer Bottleneck and Creating Value in the Biomedical Research Field," Journal of Commercial Biotechnology, 9(2): 111-118. 
Green, J. and S. Scotchmer, 1995, "On the Division of Profit in Sequential Innovation," RAND Journal of Economics, 26(1): 20-33.

Grossman, G. and C. Shapiro, 1986, "Optimal Dynamic R\&D Programs," RAND Journal of Economics, 17(4): 581-592.

Kaplow, L., 1984, "The patent-Antitrust Intersection: A Reappraisal," Harvard Law Review, 97: 1813 .

Klein, J. I., 1997, "Cross-licensing and Antitrust Law," Speech before the American Intellectual Property Law Association, in <www.usdoj.gov/atr/public/speeches/speeches.htm>

Kulbaski, J. J., 2002, "Comments on Patent Pools and Standards," Testimony before DoJ-Ftc Hearings on Competition and Intellectual property Law and Policy in the Knowledge-Based Economy, in <www.ftc.gov/opp/intellect/index.htm $>$

Lerner, J., Strojwas, M. and J. Tirole, 2003, "Cooperative Marketing Agreements Between Competitors: Evidence from Patent Pools," working paper, IDEI, Toulouse.

Lerner, J. and J. Tirole, 2003, "Efficient Patent Pools," working paper, IDEI, Toulouse.

Lind, R. C., Kleymenova, A. V., Miauton, M. and P. Muysert, 2003, Report on Multiparty Licensing, Charles River Associates Limited.

Matutes, C., Régibeau , P. and K. Rockett, 1996, "Optimal Patent Design and the Diffusion of Innovations," RAND Journal of Economics, 27(1): 60-83.

Merges, R., 1999, "Institutions for Intellectual Property Transactions: The Case of Patent Pools," working paper, University of California at Berkeley. 
Morse, M. H., 2002, "Cross-Licensing and Patent Pools: Legal Framework and Practical Issues," Antitrust and Intellectual Property, 3(1): 42-53.

Newberg, J. A., 2000, "Antitrust, Patent Pools, and the Management of Uncertainty," Atlantic Law Journal, 1(3): 1-30.

Reinganum, J., 1989, "The Timing of Innovation: Research, Development and Diffusion," Handbook of Industrial Organization, Vol. 1, chap. 14, Elsevier.

Seide, R., LeCointe, M. and A. Granovsky , 2001, "Patent Pooling in the Biotechnology Industry," The Licensing Journal, October.

Shapiro, C., 2001, "Navigating the Patent Thicket: Cross Licenses, Patent Pools and Standard Setting," Innovation Policy and the Economy, 1(1): 119-150.

Swidler Berlin Shereff Friedman LLP, 2003, "New Guidance on Patent Pools from Justice Department," Antitrust and Trade Regulation Update, March.

United States Patent and Trademark Office, 2000, "Patent Pools: A Solution to the Problem of Access in Biotechnology Patents?," mimeo. 